\title{
Thermal Stability of Shear-Induced Precursors and Their Effect on the Crystalline Structure of $\beta$-Nucleated Isotactic Polypropylene
}

\author{
Yefei Tian (iD) ${ }^{1,2}$ \\ ${ }^{1}$ School of Materials Science and Engineering, Chang'an University, Xi'an, Shaanxi 710064, China \\ ${ }^{2}$ Engineering Research Center of Transportation Materials, Ministry of Education, Chang'an University, Xi'an 710064, China \\ Correspondence should be addressed to Yefei Tian; yftian@chd.edu.cn
}

Received 26 November 2018; Revised 12 February 2019; Accepted 28 April 2019; Published 4 June 2019

Academic Editor: Cornelia Vasile

Copyright (C) 2019 Yefei Tian. This is an open access article distributed under the Creative Commons Attribution License, which permits unrestricted use, distribution, and reproduction in any medium, provided the original work is properly cited.

\begin{abstract}
The thermal stability and lifetime of shear-induced precursors under various annealing temperatures, as well as the influence of their relaxation on the crystalline modification in $\beta$-nucleated isotactic polypropylene (iPP), are investigated using an ARES rheometer. The wide-angle X-ray diffraction results show that the $\beta$-crystal content of sheared $\beta$-nucleated iPP samples gradually increases with thermal treatments. The relaxation of shear-induced precursors during annealing which caused the decrease of shear nuclei may restrain the counteraction effect between the shear flow and $\beta$-nucleation agent as well as result in the increase of $\beta$-crystal content. At the early stage of relaxation, the relaxation degree is closely related to the increase of $\beta$ crystals, for which the deeper relaxed shear-induced precursors result in the more restoration of $\beta$-crystals. However, when the relaxation degree exceeded a certain limitation, where the $\beta$-crystals reached the maximum, the relaxation of shear-induced precursors will no longer influence the crystal structure of $\beta$-nucleated iPP.
\end{abstract}

\section{Introduction}

As a widely used polymer material, isotactic polypropylene (iPP) owns tremendous commercial value, because of its various application fields. However, the poor toughness is its Achilles' heel. Thereby, how to improve the impact resistance of iPP has always been the most important problem to be solved in both industry and academia. Compared to the common modification of iPP, i.e., $\alpha$-form, $\beta$-form iPP exhibits enhanced impact resistance, which is usually attributed to the phase transformation from $\beta$ - to $\alpha$-form and the intrinsic loose structure of $\beta$-crystals that are in favor of energy dissipation $[1,2]$. The thermodynamically metastable $\beta$-form can be achieved under special conditions such as crystallization under temperature gradients $[3,4]$, under shear [5], or in the presence of specific $\beta$-nucleation agent $[6,7]$. Until now, adding $\beta$-nucleation agent is still the most effective and accessible method to obtain the iPP with a high level of $\beta$-phase crystals [8]. However, in most of the polymer processing operations used to mix $\beta$-NA and polymer, the inevitable shear force can easily orient and stretch the long and flexible polymer chain and lead to a further effect on crystalline structure formation of iPP. Hence, the shear flow effect should be taken into consideration in order to obtain relatively pure $\beta$-iPP.

The intricate shear flow effect on the crystallization of iPP can be roughly divided in three aspects. The most remarkable effect is the enhancement of the crystallization rate, which leads to significantly accelerated crystallization rates compared to crystallization under quiescent condition $[9,10]$. The second aspect is that shear flow causes an oriented crystalline structure of iPP, i.e., a shish-kebab structure, which distinguishes from the normal spherulites formed under quiescent condition $[11,12]$. The last but very important aspect is the great influence of shear flow on the crystalline phase that induces iPP to form $\beta$-phase crystals. Previous studies reported the phenomenon that a high shear rate could restrain the formation of $\beta$-crystals $[13,14]$. Li et al. [15] proposed that the oriented $\alpha$-row nuclei induced by shear flow could trigger the competitive growth of $\alpha$ - and $\beta$-crystals, which consequentially decreased the content of $\beta$-crystals in the limited growing space. In view of the fact that the 
oriented $\alpha$-row nuclei is the original cause of the complicated shear effect, we consider that investigating the inherent characteristic of the shear-induced precursors may be a breakthrough to solve this problem.

With respect to the structure of shear-induced precursors, many earlier studies have achieved a general description by means of rheometry and in situ wide-angle X-ray diffraction (WAXD), small-angle X-ray scattering (SAXS), small-angle light scattering (SALS), optical microscopy, and electron microscopy [10]. For the shear-induced precursors with a shish-kebab structure, many previous experiments [16-18] demonstrated that it can survive for long under quiescent condition, even when temperature was higher than the melting point of a semicrystalline polymer. Thereby, we consider that figuring out the relationship of thermal stability of shear-induced precursors and its effect on the crystalline structure of $\beta$-nucleated iPP may be a primary step to regulate the content of $\beta$-crystals.

In this paper, we designed an experiment which allowed getting shear-induced precursors with various relaxation degrees by controlling annealing treatment. The effect of shear-induced precursors' relaxation on isothermal crystallization kinetics and the content of $\beta$-phase crystals were investigated. Accordingly, the thermal stability and relaxation of shear-induced precursors in $\beta$-nucleated iPP were also speculated, and the relationship between the structure of shear-induced precursors and the content of $\beta$-phase crystal in $\beta$-nucleated iPP was established.

\section{Experimental}

2.1. Materials and Methods. Ziegler-Natta isotactic polypropylene (F401) was purchased from Yangzi Petrochemical Co., SINOPEC. The peak melting point obtained from the differential scanning calorimeter (DSC) is $167^{\circ} \mathrm{C}$. Aryl amide compounds (TMB-5) were used as $\beta$-nucleating agent here, which were supplied by the Shaanxi Institute of Chemical Industry. The iPP was melt mixed with TMB-5 in a weight ratio of $0.1 \mathrm{wt} \%$ in a torque rheometer $\left(180^{\circ} \mathrm{C}, 80 \mathrm{rpm}\right)$. The $\beta$-nucleated iPP was molded into $0.4 \mathrm{~mm}$ thick sheets $\left(200^{\circ} \mathrm{C}, 15 \mathrm{MPa}\right)$ and cut into disks of $25 \mathrm{~mm}$ diameter for rheological experiments.

2.2. Rheometry. An ARES rheometer with torsional parallel plate geometry combining with a temperature-controlled oven was used to provide precise control of shear flow and temperature. The torque and strain resolutions are $1 \mathrm{nN} \cdot \mathrm{m}$ and $0.04 \omega \cdot \mathrm{rad}$, respectively, and the accuracy of the temperature-controlled oven can reach $\pm 0.1^{\circ} \mathrm{C}$. The short-term shear flow was operated in a steady mode with different shear rates $\left(20\right.$ to $\left.50 \mathrm{~s}^{-1}\right)$ for $10 \mathrm{~s}$. The dynamic oscillatory mode was carried out to monitor the course of crystallization. The change of storage modulus $G^{\prime}$ and loss modulus $G^{\prime \prime}$ with time was tracked. Khanna [19] proposed a method to describe the crystallization behavior of a polymer by rheological characterization. They gave a relationship for the transformed fraction, $\alpha(t)$, as a function of storage modulus $G^{\prime}$ :

$$
a(t)=\frac{G^{\prime}(t)-G_{0}^{\prime}}{G_{\infty}^{\prime}-G_{0}^{\prime}}
$$

where $G^{\prime}(t), G_{0}^{\prime}$, and $G_{\infty}^{\prime}$ are the storage moduli at time $t, 0$, and infinity. The value of $\alpha(t)$ is a time-dependent parameter to reflect the degree of crystallization.

2.3. Thermal-Shear Protocol. The applied thermomechanical profile for ARES tests is shown in Figure 1. The disk sample was heated to $210^{\circ} \mathrm{C}$ for $5 \mathrm{~min}$ to erase the thermal history, and then, the sample was fast cooled to shear temperature, $T_{\mathrm{S}}$. The shear temperature was selected as $170^{\circ} \mathrm{C}$ that was higher than the actual melting point of iPP spherulites. The shear pulse was applied to the melt for $10 \mathrm{~s}$ at a shear rate of $40 \mathrm{~s}^{-1}$. To investigate the thermal stability of shear-induced precursors, the sample was heated to relaxation temperature $\left(T_{\mathrm{R}}\right)$ that ranged between $T_{\mathrm{S}}$ and $190^{\circ} \mathrm{C}$ for a different time. The sample was program-controlled cooled to the crystallization temperature $\left(T_{\mathrm{C}}=135^{\circ} \mathrm{C}\right)$ at a rate of $30^{\circ} \mathrm{C} / \mathrm{min}$ and held at this temperature isothermally until complete crystallization.

2.4. Wide-Angle X-Ray Diffraction Measurement. WAXD measurements were carried out on a PANalytical X'Pert diffractometer (PANalytical, Netherlands) in a reflection mode using Ni-filtered $\mathrm{CuK}_{\alpha}$ irradiation $(\lambda=0.154 \mathrm{~nm})$ under a voltage of $40 \mathrm{kV}$ and a current of $40 \mathrm{~mA}$. Intensity versus diffraction angle $2 \theta$ was recorded in the region from 10 to $30^{\circ}$. Subsequently, through deconvoluting the peaks in linear WAXD profiles, the relative content of the $\beta$-crystals $K_{\beta}$ was evaluated by the method that Turner Jones et al. [20] proposed:

$$
K_{\beta}=\frac{I_{\beta}(300)}{I_{\beta}(300)+I_{\alpha}(110)+I_{\alpha}(040)+I_{\alpha}(130)},
$$

where $I_{\beta}(300)$ is the intensity of the (300) reflection peak and $I_{\alpha}(110), I_{\alpha}(040)$, and $I_{\alpha}(130)$ are the intensities of the (110), (040), and (130) reflection peaks, respectively.

\section{Results and Discussion}

3.1. Thermal Stability and Lifetime of Shear-Induced Nucleation Precursors in Pure and $\beta$-Nucleated iPP. The crystallization curves of pure and $\beta$-nucleated iPP which relaxed for a different time are shown in Figure 2. The shear pulse was applied at $170^{\circ} \mathrm{C}$ for $10 \mathrm{~s}$, and then, relaxation was conducted at the same temperature for different durations. The change of $G^{\prime}$ during isothermal crystallization at $135^{\circ} \mathrm{C}$ was tracked to investigate the crystallization process of iPP and $\beta$-nucleated iPP. For both pure iPP and nucleated iPP, the sheared samples present the fastest crystallization rates, while the quiescent samples present the slowest crystallization rates. The relaxation treatment at $170^{\circ} \mathrm{C}$ obviously decelerates the crystallization rates of either iPP or $\beta$-nucleated iPP compared with samples that have not been relaxed, and longer relaxation time makes the crystallization rates of relaxed samples closer to the quiescent samples, which is in 


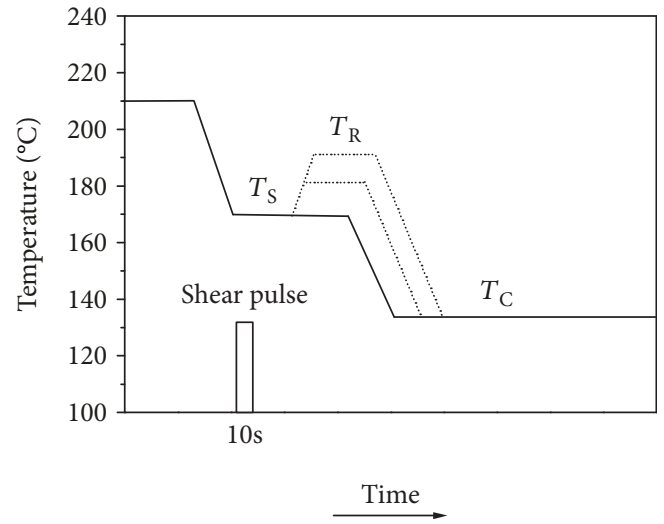

FIgURE 1: Schematic diagram of the temperature-shear protocol.

agreement with previous studies that also found that relaxation caused attenuation of shear-enhanced crystallization because of the dissolution of shear-induced nucleation precursors $[17,18]$. The relaxation temperature was set close to the processing temperature in realistic production which was lower than the equilibrium melting point of iPP to mimic thermal treatment in real processing. Both iPP and $\beta$-nucleated iPP are in their melt state at the relaxation temperature, while the thermal history of both samples cannot be erased.

To quantitatively evaluate the relaxation behavior of shear-induced precursors, a dimensionless factor proposed by Cavallo et al. [17] was introduced in this work. It is defined as the relative shear efficiency (RSE) which represents the residual effect of shear on the crystallization rate:

$$
\mathrm{RSE}=\frac{\left.t_{0.1}\left(t_{R}\right)-t_{0.1} \text { (quiescent }\right)}{t_{0.1}\left(t_{R}=0\right)-t_{0.1}(\text { quiescent })}
$$

where $t_{0.1}\left(t_{R}\right), t_{0.1}\left(t_{R}=0\right)$, and $t_{0.1}$ (quiescent) are the time when the transformed fraction, $\alpha(t)$, equals to 0.1 , for samples which have been relaxed at high temperature for a time $t_{R}$, for samples immediately quenched to $T_{\mathrm{C}}$ after shear, and for unsheared samples, respectively. The value of $\alpha(t)$ is calculated by equation (1). As mentioned in Experimental, the evolution of $G^{\prime}$ with time could be used as an indicator of relative crystallinity. When $\alpha(t)$ is less than 0.1 , the initial stage of crystallization mainly involved the nucleation process with rare interference of the crystallite growing process [15]. Thereby, we modified the conception of RSE by using the time when $\alpha(t)$ is 0.1 to replace the half-crystallization time. According to the definition, the value of RSE lies between 0 and 1 . The value 1 stands for the maximum shear efficiency when samples have not experienced relaxation, and 0 stands for the minimum shear efficiency when samples crystallized under quiescent condition. RSE only reflects the relaxation behavior leading to dissolution of shear-induced precursors but does not provide direct information of inherent character of shear-induced precursors. The value of RSE calculated by equation (3), as a function of relaxation time for iPP and $\beta$-nucleated iPP, is plotted in Figure 3. The linear decrease of RSE with increasing of relaxation duration can be observed for both samples. However, there is a great discrepancy of the decreasing rate between pure iPP and $\beta$ nucleated iPP. The relaxation rate of shear-induced precursors in pure iPP is much faster than those in $\beta$-nucleated iPP. It is expected that the gradual dissolution of the shearinduced nucleation precursor during high temperature relaxation is the main reason for the attenuation of shear efficiency. Thereby, the different relaxation rates of two samples result from the different thermal stabilities of their shear-induced precursors. Previous studies found that the surface of large particles could stabilize extended chain conformations due to the surface contact points acting as physical cross-links [21]. Similarly, nanoparticles which have a strong affinity for a polymer molecule have been found the analogous effect [22]. Based on the experimental results, we believe that the introduction of foreign particles largely limited the mobility of polymer chains, meanwhile acting as physical cross-links in the flow-induced oriented structure. As a result, the nucleation agent particles stabilized the shear-induced precursors retarding the relaxation process of these precursors.

3.2. Activation Energies of Shear-Induced Precursors in $\beta$ Nucleated iPP. To better understand the thermal stability of shear-induced precursors in $\beta$-nucleated iPP, additional relaxation temperatures were set for comparison. Figure 4 shows the $G^{\prime}$ curves of $\beta$-nucleated iPP relaxed at $180^{\circ} \mathrm{C}$ and $190^{\circ} \mathrm{C}$ for different times. It shows that the crystallization of samples decelerated fast after relaxation at $180^{\circ} \mathrm{C}$ and $190^{\circ} \mathrm{C}$, while the shear-enhanced crystallization did not disappear completely even if it relaxed at $190^{\circ} \mathrm{C}$ that means shear-induced precursors could almost survive in real processing. Figure 5 shows the evolution of RSE as a function of relaxation time for different relaxation temperatures $\left(170^{\circ} \mathrm{C}, 180^{\circ} \mathrm{C}\right.$, and $\left.190^{\circ} \mathrm{C}\right)$. For samples relaxed at $190^{\circ} \mathrm{C}$, the relaxation rate is faster than samples relaxed at $170^{\circ} \mathrm{C}$ and $180^{\circ} \mathrm{C}$. Obviously, the decreasing rate of RSE is significantly dependent on the value of $T_{R}$, suggesting that temperature plays a key role in dissolution of shear-induced precursors. Earlier literatures defined the lifetime of the shear-induced precursor as the time required for the relaxation process to completely eliminate shear effects, which can be determined by morphology observation or crystallization kinetic comparison [16, 17]. Here, the time for sheared samples to completely eliminate the enhancement of the crystallization rate is the relaxation time needed when RSE equals to 0 . Therefore, the lifetime of shear-induced precursors can be determined by extrapolating the straight line in Figure 5 to $\mathrm{RSE}=0$. Based on the RSE data, the calculated lifetime of shear-induced precursors at 170,180 , and $190^{\circ} \mathrm{C}$ is 3600,1100 , and $500 \mathrm{~s}$, respectively.

As suggested by Janeschitz-Kriegl and Eder and other earlier studies in relaxation of shear-induced precursors, relaxation of shear-induced precursors follows an Arrhenius-type dependence [23]. The kinetics governing annealing at high temperatures obeys time-temperature superposition, with an apparent Arrhenius activation energy, and this activation energy is much larger than the flow activation energy, since the process of shear-induced precursor relaxation involves a detachment of polymer chain segments from the oriented 


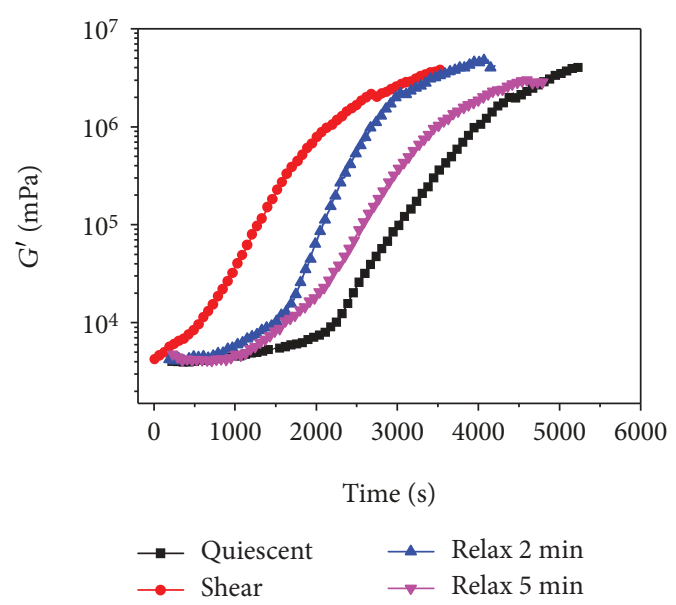

(a)

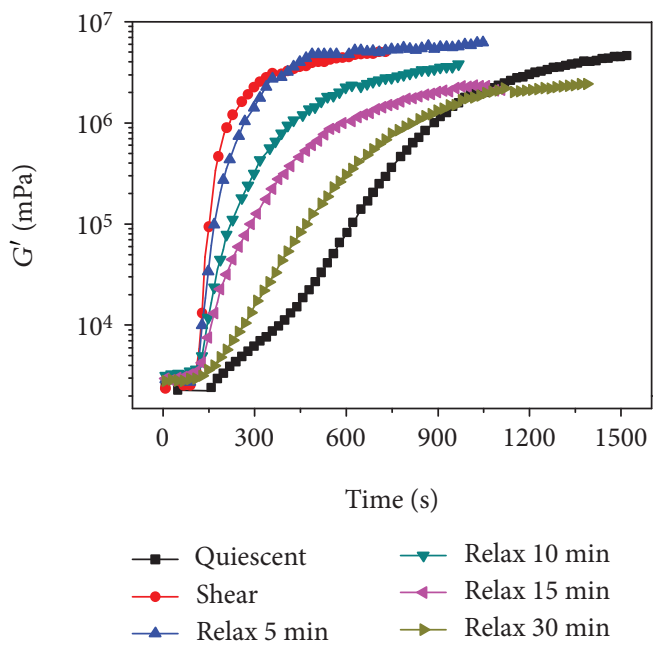

(b)

FIGURE 2: Evolution of the storage modulus $G^{\prime}$ during isothermal crystallization at $135^{\circ} \mathrm{C}$ in (a) iPP and (b) $\beta$-nucleated iPP under quiescent, sheared, and partially relaxed conditions (shear rate $=40 \mathrm{~s}^{-1}$, shear time $=10 \mathrm{~s}, T_{\mathrm{S}}=170^{\circ} \mathrm{C}$, and $T_{\mathrm{R}}=170^{\circ} \mathrm{C}$ ).

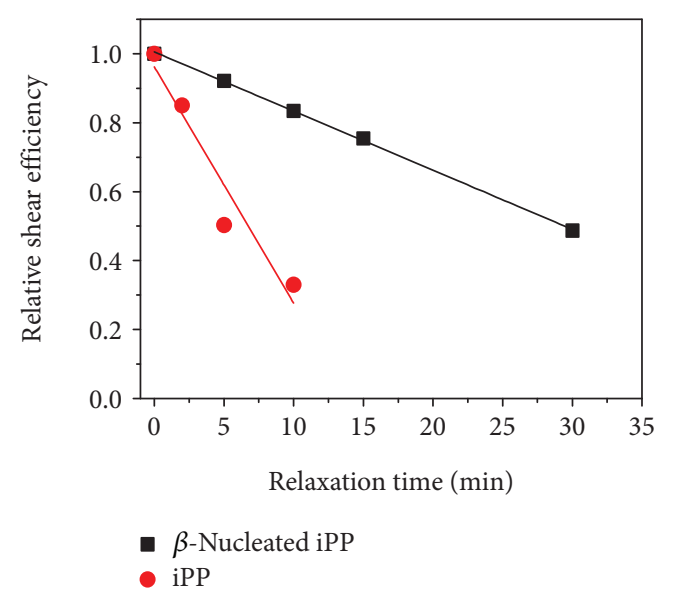

FIGURE 3: Relative shear efficiency as a function of time for pure iPP and $\beta$-nucleated iPP. Flow condition: shear rate $=40 \mathrm{~s}^{-1}$, shear time $=10 \mathrm{~s}, T_{\mathrm{S}}=170^{\circ} \mathrm{C}$, and $T_{\mathrm{R}}=170^{\circ} \mathrm{C}$.

nuclei and subsequent diffusion into the melt. Here, the temperature dependence of lifetime and apparent activation energy for shear-induced precursors can also be described by a deformation Arrhenius equation, as previous works of Cavallo et al. [17]:

$$
\tau(T)=\tau_{0} \exp \left(\frac{E_{a}}{R T}\right)
$$

where $R$ is universal gas constant $(8.314 \mathrm{~J} / \mathrm{K} \cdot \mathrm{mol}), \tau_{0}$ is material constant, $T$ is the absolute temperature $(\mathrm{K})$, and $\tau(T)$ is the lifetime at certain temperature. By substitution of the value of lifetime into equation (4), the value of activation energy for shear-induced precursors is calculated around $170 \pm 20 \mathrm{~kJ} / \mathrm{mol}$. This result is close to the value of the iPP precursor (ca. $200 \mathrm{~kJ} / \mathrm{mol}$ ) proposed by Janeschitz-Kriegl
[24], $210 \mathrm{~kJ} / \mathrm{mol}$ calculated by Cavallo et al. [17], and $160 \mathrm{~kJ} / \mathrm{mol}$ calculated by Fan et al. [18] and is much larger than the energy of activation for viscous flow $(\sim 44 \mathrm{~kJ} / \mathrm{mol}$ for iPP) [25] suggesting that the detachment of polymer chain segments from the oriented nuclei is the limiting step in the process of shear-induced precursor relaxation not diffusion of the detached stem into the melt.

3.3. Effect of Shear and Subsequent Relaxation on the Crystalline Structure. Figure 6 shows the WAXD curves of iPP containing $\beta$-nucleation agent under quiescent and shear conditions. Under quiescent condition, only the (300) reflection of $\beta$-form crystals is clearly seen at $2 \theta=16.0^{\circ}$. However, an obvious difference is observed under shear condition. Other three peaks at $2 \theta$ of approximate values 14.2, 17.0, and $18.7^{\circ}$ were present, which correspond to the (110), (040), and (130) reflections of $\alpha$-form crystals of iPP, respectively. This indicates that shear flow can engender more $\alpha$ form crystals in $\beta$-nucleated iPP. We calculated the relative content of the $\beta$-crystals, $K_{\beta}$, by using equation 2 from the WAXD data. The relative content of the $\beta$-crystals for the quiescent crystallized sample is around 0.97 , while $K_{\beta}$ decreases to about 0.81 for the sheared sample. To further understand the influence of shear flow on the formation of $\beta$-crystals for $\beta$-nucleated iPP, samples sheared under different shear rates were tested by WAXD. As shown in Figure 7, the (300) reflection of $\beta$-form crystals at $2 \theta=16.0^{\circ}$ becomes weaker when experiencing a more intense shear pulse, meanwhile the principal reflection of $\alpha$-crystal at $2 \theta=14.2,17.0$, and 18.7 becomes stronger. It suggests that shear condition indeed obstructs the formation of $\beta$-crystals for the nucleated iPP system.

To investigate the influence of relaxation on the crystalline structure, partially relaxed samples with various thermal annealing times were tested by WAXD, and Figure 8 illustrates the WAXD patterns of $\beta$-nucleated iPP relaxed at 


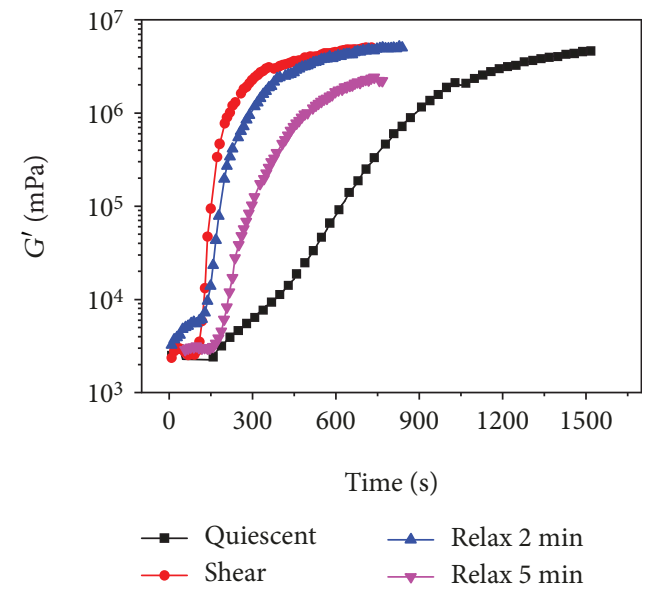

(a)

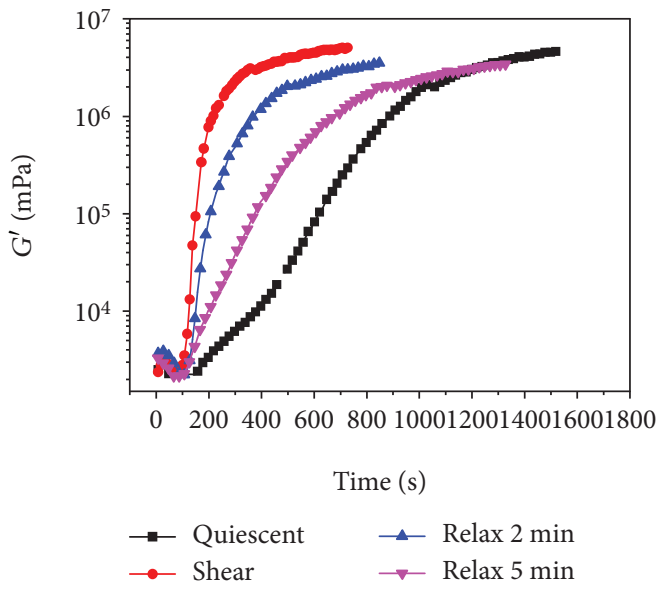

(b)

FIgURE 4: Evolution of the storage modulus $G^{\prime}$ during isothermal crystallization at $135^{\circ} \mathrm{C}$ for $\beta$-nucleated iPP agent relaxed at different temperatures: (a) $T_{\mathrm{R}}=180^{\circ} \mathrm{C}$ and (b) $T_{\mathrm{R}}=190^{\circ} \mathrm{C}$. Flow condition: shear rate $=40 \mathrm{~s}^{-1}$, shear time $=10 \mathrm{~s}$, and $T_{\mathrm{S}}=170^{\circ} \mathrm{C}$.

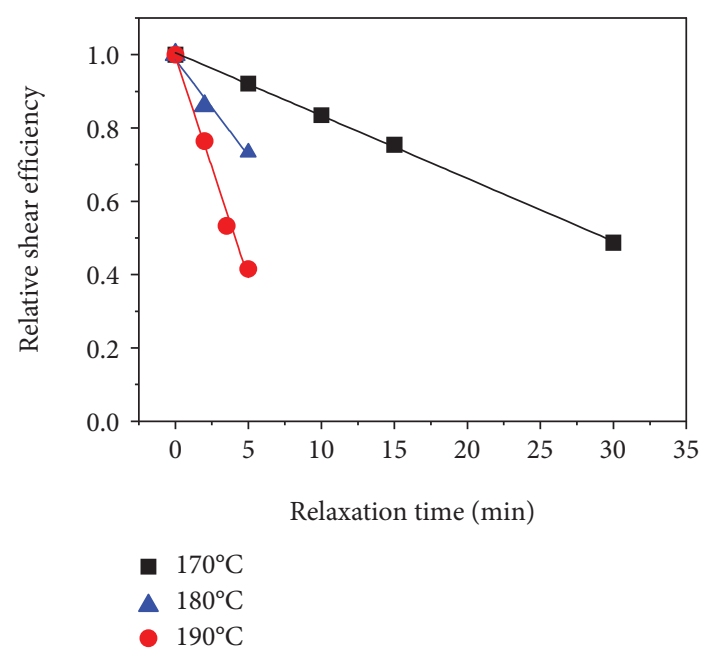

FIGURE 5: Relative shear efficiency as a function of time at different relaxation temperatures for $\beta$-nucleated iPP. Flow condition: shear rate $=40 \mathrm{~s}^{-1}$, shear time $=10 \mathrm{~s}$, and $T_{\mathrm{S}}=170^{\circ} \mathrm{C}$.

$170^{\circ} \mathrm{C}$ after shearing. For the sheared sample without relaxation, the principal reflection of $\alpha$-crystal at $2 \theta=14.2,17.0$, and 18.7 can be easily seen. However, the three peaks gradually disappeared with the prolonging of relaxation time. When samples were relaxed at $170^{\circ} \mathrm{C}$ for more than 15 minutes, the three peaks of $\alpha$-crystal had already become hard to be seen. It demonstrated that relaxation not only eliminates the enhancement of crystallization rates but also frees the restraint of formation of $\beta$-crystal caused by shear flow.

We systemically investigate the evolution of the crystal phase with relaxation. The value of $K_{\beta}$ and relative shear efficiency of $\beta$-nucleated iPP under different relaxed conditions is shown in Table 1 . For samples relaxed at $170^{\circ} \mathrm{C}$ for $5 \mathrm{~min}$, the $K_{\beta}$ becomes 0.87 , which has a big increase compared to the value of the sheared sample, 0.81 . For samples relaxed for $30 \mathrm{~min}$, the $K_{\beta}$ increases to 0.97 , which is very close to the value of $\beta$-nucleated iPP without experiencing shearing.
It is obvious that the relative $\beta$-phase content of samples increases with the prolonging of relaxation duration at all three temperatures. The only discrepancy is that the increase rate of $K_{\beta}$ is quite different for three relaxation temperatures. As relaxed at $190^{\circ} \mathrm{C}$, the $K_{\beta}$ increases to 0.97 only after $5 \mathrm{~min}$ relaxation. The introduction of shear flow results in a decrease of $\beta$-phase content in $\beta$-nucleated iPP, while the loss of $\beta$-phase content can restore its original value after experiencing the thermal annealing. We believe that this restoration must be related to the relaxation of shear-induced precursors, and consequently, the degree of restoration of relative $\beta$-phase content during relaxation may be determined by the extent of relaxation. To invalidate this perspective, we compared the relationship between the relative shear efficiency and $K_{\beta}$ in Figure 9. The $K_{\beta}$ keeps increasing with the decrease of RSE until it comes to the maximum value, that is, the value of the unsheared sample. The decrease of RSE means the attenuation of shear effect, as well as the dissolution of shear-induced precursors. Clearly, the dissolution of shear-induced precursors helps to cause a restoration of $\beta$ phase content. It is worth to notice that, when the relative shear efficiency decreases lower than 0.75 , the $\beta$-phase content has got back to the maximum value. Thereby, the increase of $\beta$-phase content did not synchronize with the decay of shear effect. It means that the shear effect on the crystal structure disappeared, even if the shear-induced precursors have not dissolved completely. It inspires us that the sheared $\beta$-nucleated iPP could be laid at temperature close to the real processing temperature (i.e., 170, 180, and $190^{\circ} \mathrm{C}$ ) for a short time after shearing to eliminate the effect of shear on the crystalline structure and obtain high-purity $\beta$-phase iPP.

\section{Conclusions}

In conclusion, the relaxation behavior of the shear-induced nucleation precursor has been systematically investigated by 


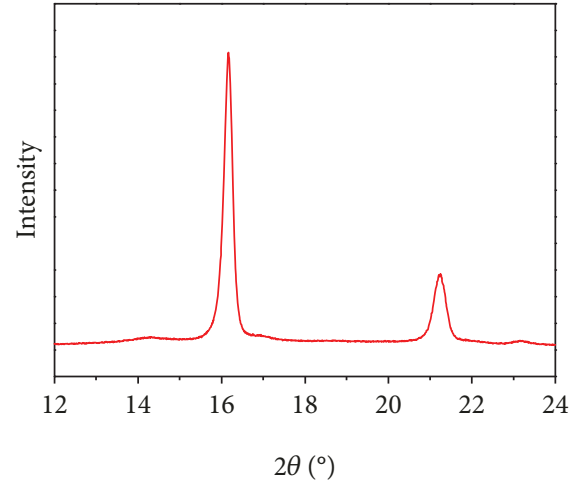

(a)

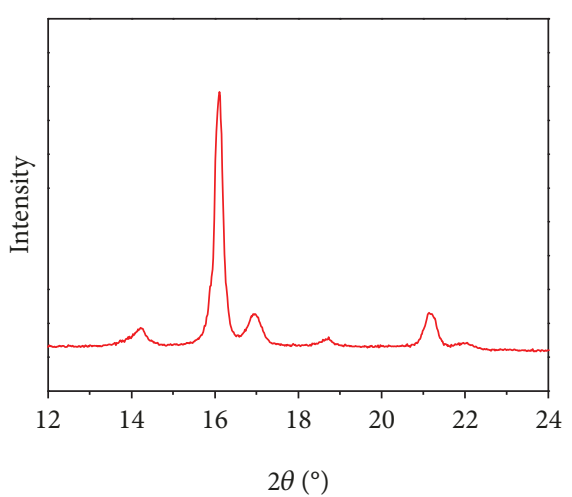

(b)

Figure 6: WAXD patterns of $\beta$-nucleated iPP crystallized at $135^{\circ} \mathrm{C}$ under (a) quiescent condition and (b) shear condition $\left(\right.$ shear rate $=40 \mathrm{~s}^{-1}$, shear time $=10 \mathrm{~s}$, and $\left.T_{\mathrm{S}}=170^{\circ} \mathrm{C}\right)$.

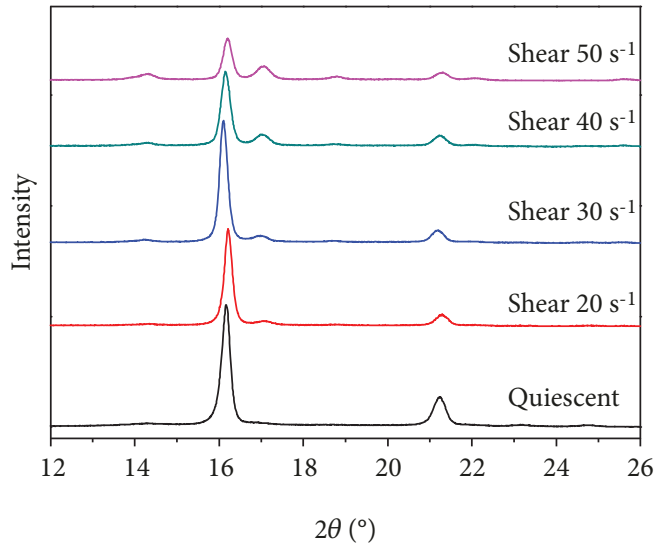

FIgURE 7: WAXD patterns of $\beta$-nucleated iPP sheared at $170^{\circ} \mathrm{C}$ for $10 \mathrm{~s}$ under different shear rates.

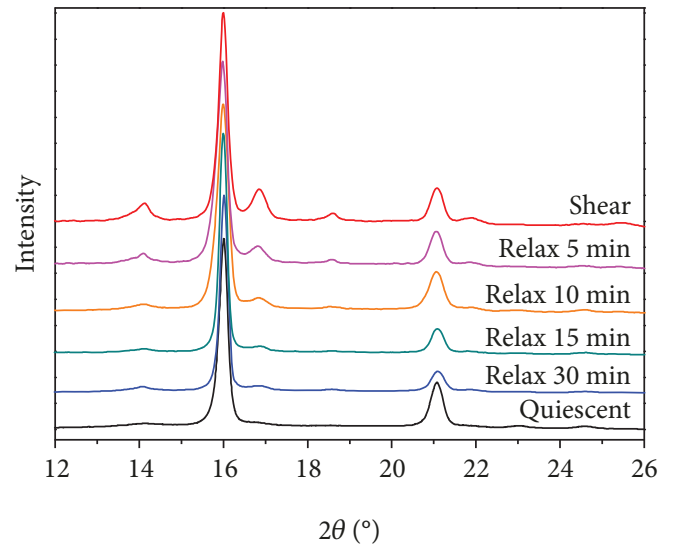

Figure 8: WAXD patterns of $\beta$-nucleated iPP relaxed at $170^{\circ} \mathrm{C}$ for different times after shearing (shear rate $=40 \mathrm{~s}^{-1}$, shear time $=10 \mathrm{~s}$, and $\left.T_{\mathrm{S}}=170^{\circ} \mathrm{C}\right)$.

means of the ARES rheometer. The enhanced crystallization rates gradually faded away when samples were held at a high temperature above the melting point. A linear decrease of RSE with the increase of relaxation duration was observed both in pure iPP and $\beta$-nucleated iPP. It demonstrated that foreign particles could stabilize the shear-induced precursors
TABLE 1: Relative $\beta$-phase content and relative shear efficiency of $\beta$ nucleated iPP under different relaxed conditions.

\begin{tabular}{lcccc}
\hline $\begin{array}{l}\text { Crystallization } \\
\text { condition }\end{array}$ & $\begin{array}{c}\text { Relaxation } \\
\text { temperature }\left({ }^{\circ} \mathrm{C}\right)\end{array}$ & $\begin{array}{c}\text { Relaxation } \\
\text { time }(\mathrm{min})\end{array}$ & RSE & $K_{\beta}$ \\
\hline Quiescent & - & - & 0 & 0.97 \\
Sheared & - & - & 1 & 0.81 \\
& 170 & 5 & 0.92 & 0.87 \\
& 170 & 10 & 0.83 & 0.92 \\
& 170 & 15 & 0.75 & 0.95 \\
Partially relaxed & 170 & 30 & 0.48 & 0.97 \\
& 180 & 2 & 0.86 & 0.93 \\
& 180 & 5 & 0.73 & 0.96 \\
& 190 & 2 & 0.76 & 0.95 \\
& 190 & 3 & 0.53 & 0.96 \\
& 190 & 5 & 0.42 & 0.97 \\
\hline
\end{tabular}

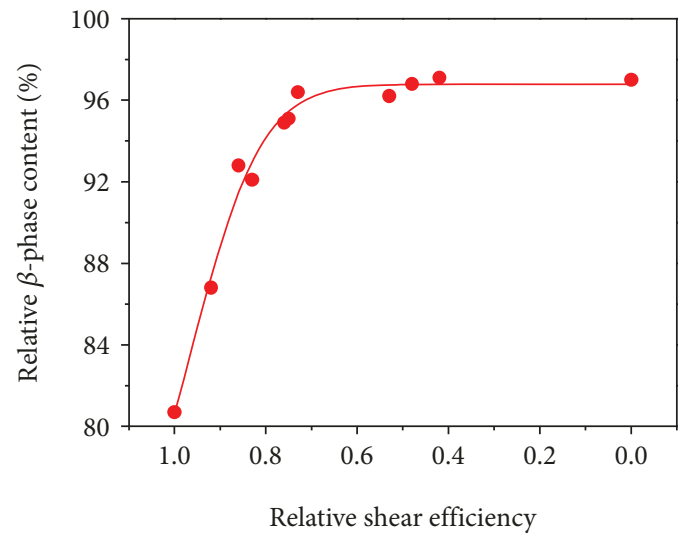

Figure 9: Relative $\beta$-phase content as a function of relative shear efficiency for $\beta$-nucleated iPP.

and consequently retard the relaxation process, thereby endowing the precursors in $\beta$-nucleated iPP with higher thermal stability. The effect of shear and subsequent relaxation on the crystalline structure has been studied. It is found that the relaxation can free the restraint effect of shear flow on the formation of $\beta$-crystals, as well as restore the loss of 
$\beta$-phase crystal content caused by shear flow, while the increase of $\beta$-phase content did not synchronize with the decay of shear effect. The thermal treatment as relaxation at processing temperature (i.e., $190^{\circ} \mathrm{C}$ ) for a short time (i.e., $5 \mathrm{~min}$ ) duration could fully erase the negative effect of shear on the formation of $\beta$-crystals for $\beta$-nucleated iPP.

\section{Data Availability}

The data used to support the findings of this study are available from the corresponding author upon request.

\section{Conflicts of Interest}

The authors declare that there is no conflict of interests regarding the publication of this article.

\section{Acknowledgments}

We acknowledge the support from the National Science Foundation of China (Grant No. 51703010), China Postdoctoral Science Foundation (Nos. 2017M623092 and 2018T111007), and Special Fund for Basic Scientific Research of Central College of Chang'an University (No. 300102319206). The authors gratefully acknowledge their financial support.

\section{References}

[1] S. C. Tjong, J. S. Shen, and R. K. Y. Li, "Impact fracture toughness of $\beta$-form polypropylene," Scripta Metallurgica et Materialia, vol. 33, no. 3, pp. 503-508, 1995.

[2] H. B. Chen, J. Karger-Kocsis, J. S. Wu, and J. Varga, "Fracture toughness of $\alpha$ - and $\beta$-phase polypropylene homopolymers and random- and block-copolymers," Polymer, vol. 43, no. 24, pp. 6505-6514, 2002.

[3] V. H. J. Leugering, "Einflu $\beta$ der kristallstruktur und der überstruktur auf einige eigenschaften von polypropylen," Die Makromolekulare Chemie, vol. 109, no. 1, pp. 204-216, 1967.

[4] Y. Fujiwara, "Das Doppelschmelzverhalten $\operatorname{der} \beta$-Phase des isotaktischen Polypropylens," Colloid \& Polymer Science, vol. 253, no. 4, pp. 273-282, 1975.

[5] J. Varga and J. Karger-Kocsis, "Rules of supermolecular structure formation in sheared isotactic polypropylene melts," Journal of Polymer Science Part B: Polymer Physics, vol. 34, no. 4, pp. 657-670, 1996.

[6] J. Varga, I. Mudra, and G. W. Ehrenstein, "Highly active thermally stable $\beta$-nucleating agents for isotactic polypropylene," Journal of Applied Polymer Science, vol. 74, no. 10, pp. 23572368, 1999.

[7] C. Mathieu, A. Thierry, J. C. Wittmann, and B. Lotz, "Specificity and versatility of nucleating agents toward isotactic polypropylene crystal phases," Journal of Polymer Science Part B: Polymer Physics, vol. 40, no. 22, pp. 2504-2515, 2002.

[8] M. Fujiyama, "Structure and properties of injection moldings of $\beta$-crystal nucleator-added polypropylene," International Polymer Processing, vol. 10, no. 3, pp. 251-254, 1995.

[9] M. R. Mackley and A. Keller, "Flow induced crystallization of polyethylene melts," Polymer, vol. 14, no. 1, pp. 16-20, 1973.

[10] G. Kumaraswamy, A. M. Issaian, and J. A. Kornfield, "Shear-enhanced crystallization in isotactic polypropylene. 1. Correspondence between in situ rheo-optics and ex situ structure determination," Macromolecules, vol. 32, no. 22, pp. 7537-7547, 1999.

[11] Y.-H. Chen, G.-J. Zhong, Y. Wang, Z.-M. Li, and L. Li, "Unusual tuning of mechanical properties of isotactic polypropylene using counteraction of shear flow and $\beta$-nucleating agent on $\beta$-form nucleation," Macromolecules, vol. 42, no. 12, pp. 4343-4348, 2009.

[12] C. Zhang, H. Hu, X. Wang et al., "Formation of cylindrite structures in shear-induced crystallization of isotactic polypropylene at low shear rate," Polymer, vol. 48, no. 4, pp. 11051115, 2007.

[13] J. Varga, " $\beta$-Modification of polypropylene and its twocomponent systems," Journal of Thermal Analysis, vol. 35, no. 6, pp. 1891-1912, 1989.

[14] H. Huo, S. Jiang, L. An, and J. Feng, "Influence of shear on crystallization behavior of the $\beta$ phase in isotactic polypropylene with $\beta$-nucleating agent," Macromolecules, vol. 37, no. 7, pp. 2478-2483, 2004.

[15] Y. H. Chen, Y. M. Mao, Z. M. Li, and B. S. Hsiao, "Competitive growth of $\alpha$ - and $\beta$-crystals in $\beta$-nucleated isotactic polypropylene under shear flow," Macromolecules, vol. 43, no. 16, pp. 6760-6771, 2010.

[16] R. H. Somani, I. Sics, and B. S. Hsiao, "Thermal stability of shear-induced precursor structures in isotactic polypropylene by rheo-X-ray techniques with couette flow geometry," Journal of Polymer Science Part B: Polymer Physics, vol. 44, no. 24, pp. 3553-3570, 2006.

[17] D. Cavallo, F. Azzurri, L. Balzano, S. S. Funari, and G. C. Alfonso, "Flow memory and stability of shear-induced nucleation precursors in isotactic polypropylene," Macromolecules, vol. 43, no. 22, pp. 9394-9400, 2010.

[18] J. Fan, Q. Zhang, D. Hu, Q. Ren, and J. Feng, "Relaxation behavior of shear-induced crystallization precursors in isotactic polypropylene containing sorbitol-based nucleating agents with different nucleating abilities," Physical Chemistry Chemical Physics, vol. 18, no. 13, pp. 8926-8937, 2016.

[19] Y. P. Khanna, "Rheological mechanism and overview of nucleated crystallization kinetics," Macromolecules, vol. 26, no. 14, pp. 3639-3643, 1993.

[20] A. T. Jones, J. M. Aizlewood, and D. R. Beckett, "Crystalline forms of isotactic polypropylene," Die Makromolekulare Chemie, vol. 75, no. 1, pp. 134-158, 1964.

[21] P.-W. Zhu, G. Edward, and L. Nichols, "Effect of additives on distributions of lamellar structures in sheared polymer: a study of synchrotron small-angle X-ray scattering," Journal of Physics D: Applied Physics, vol. 42, no. 24, p. 245406, 2009.

[22] B. X. Fu, L. Yang, R. H. Somani et al., "Crystallization studies of isotactic polypropylene containing nanostructured polyhedral oligomeric silsesquioxane molecules under quiescent and shear conditions," Journal of Polymer Science Part B: Polymer Physics, vol. 39, no. 22, pp. 2727-2739, 2001.

[23] H. Janeschitz-Kriegl and G. Eder, "Shear induced crystallization, a relaxation phenomenon in polymer melts: a re-collection," Journal of Macromolecular Science, Part B, vol. 46, no. 3, pp. 591-601, 2007.

[24] H. Janeschitz-Kriegl, Crystallization Modalities in Polymer Melt Processing, Springer Verlag, Vienna, 2009.

[25] D. W. Van Krevelen, Properties of Polymers, Elsevier, Amsterdam, 1990. 


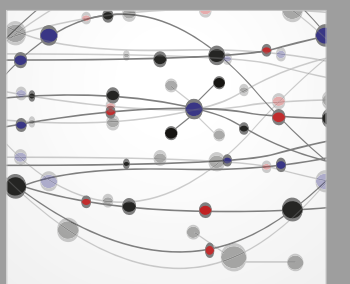

The Scientific World Journal
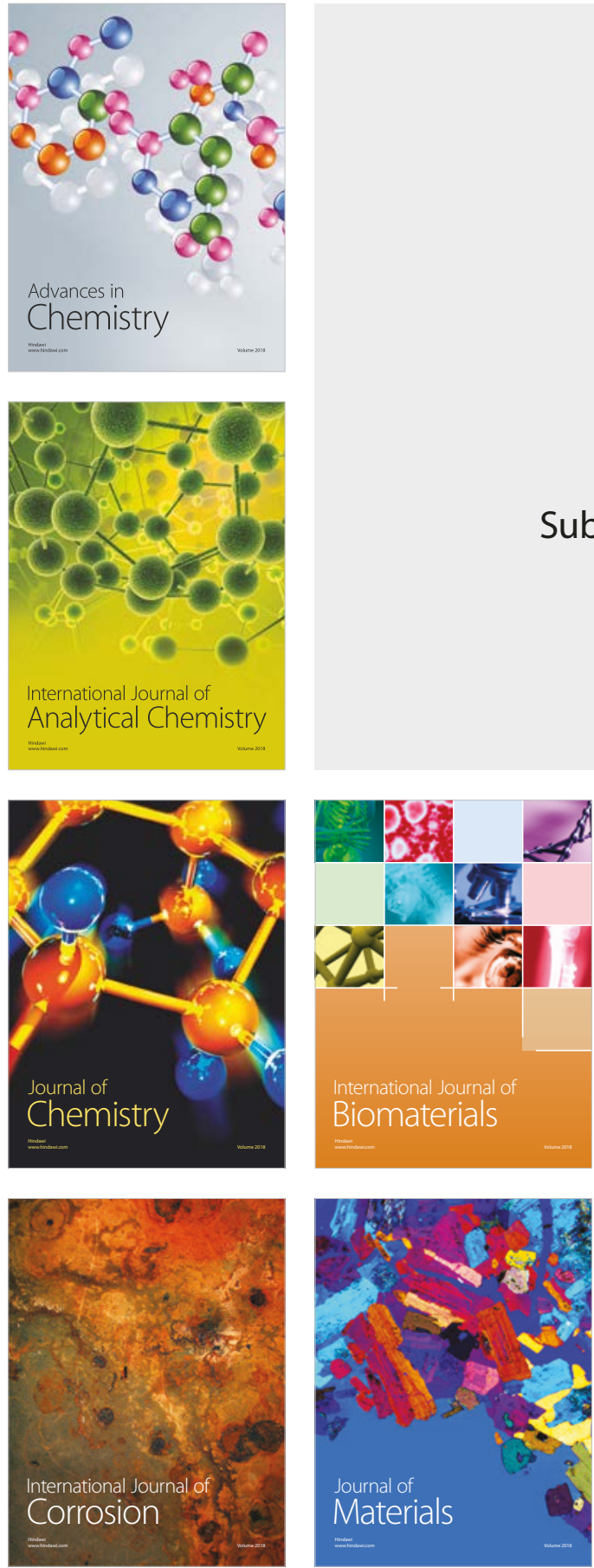

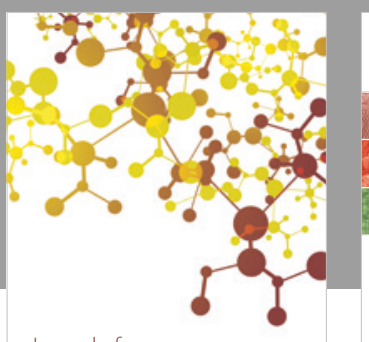

Journal of

Applied Chemistry
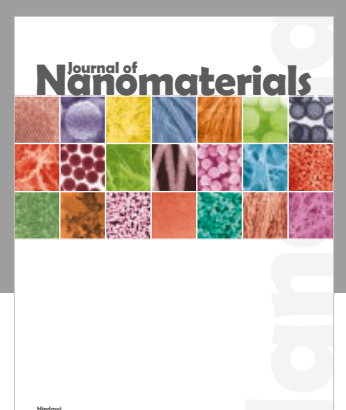

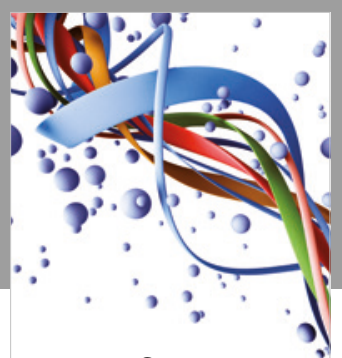

Scientifica

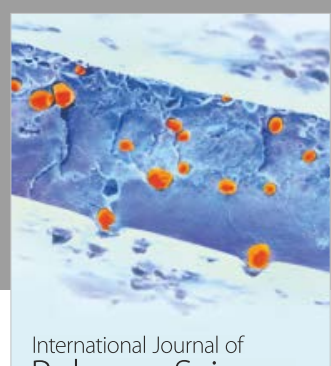

Polymer Science

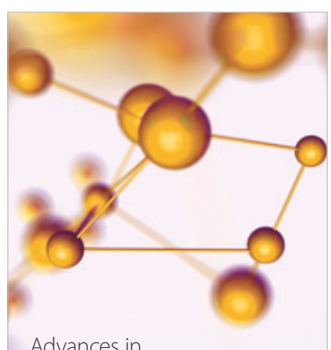

Physical Chemistry
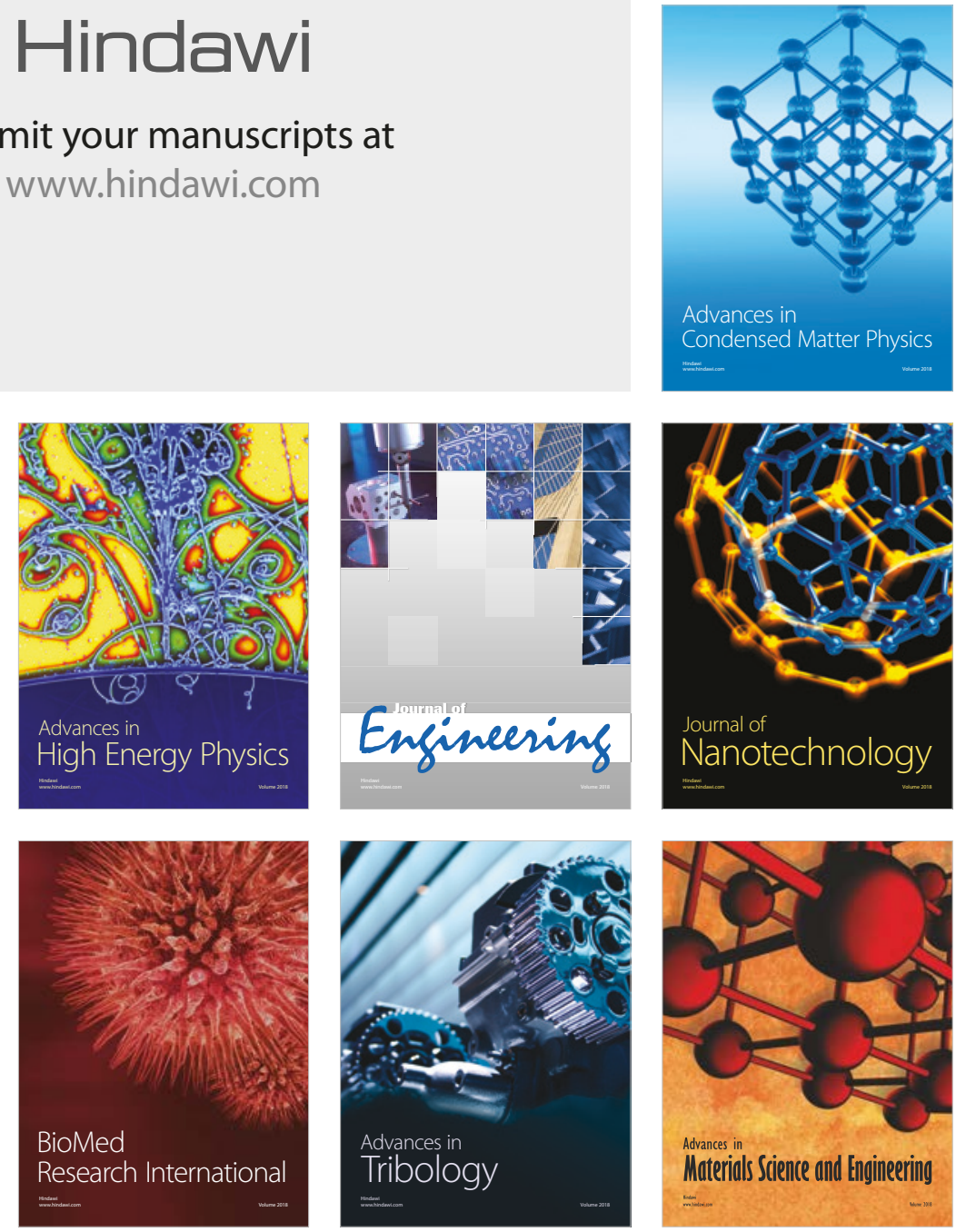